\title{
Performance Prediction of the Ferrous Metal Smelting and Rolling Processing Industry in Supply-Side Structural Reform in China
}

\author{
Kaihe Shi $\mathbb{D}^{1}{ }^{1}$ Danning Du, ${ }^{2}$ and Xiaoxuan $\mathrm{Zhang}^{3}$ \\ ${ }^{1}$ School of Management, Tianjin University of Technology, Tianjin 300384, China \\ ${ }^{2}$ School of Political Science and Public Administration, Wuhan University, Wuhan 430072, China \\ ${ }^{3}$ School of Accounting and Financial Management, University of Waterloo, Waterloo N2L 3G1, Canada \\ Correspondence should be addressed to Kaihe Shi; skh1166@163.com
}

Received 16 June 2021; Accepted 19 November 2021; Published 30 November 2021

Academic Editor: Lifeng Wu

Copyright (C) 2021 Kaihe Shi et al. This is an open access article distributed under the Creative Commons Attribution License, which permits unrestricted use, distribution, and reproduction in any medium, provided the original work is properly cited.

Supply-side structural reforms and environmental protection policies have a great impact on the ferrous metal smelting and rolling processing industry. This paper uses a grey model that introduces a fractional-order cumulative generating operator to study the development of ferrous metal smelting and rolling processing enterprises under the influence of supply-side structural reform in order to derive the future development trend of the industry. The forecast results show that from 2018 to 2022 , the number of enterprises and substitute enterprises, inventory, finished products, and assets and liabilities decreases; the scale of income of metal smelting and rolling processing industry increases. The results can serve as a reference for policy makers and industry investors.

\section{Introduction}

In recent years, the development of China's ferrous metal smelting and rolling processing industry (FRI) has been volatile. Fluctuation in price of ferrous metal has been exerting pressure on ferrous metal smelting and rolling processing companies. The impact of these measures on China's ferrous metal smelting and rolling processing industry continues to increase with the strengthening of supply-side structural reforms and increased environmental protection policies [1]. It is expected that relevant policies will continue to exert pressure on the industry in the future. Currently, China is in the middle to late stage of industrial development [2]. The industry is facing relatively high development pressure [3].

The forecasting of FRI indicators is helpful to provide a reference for the development of FRI. Moreover, it can provide a basis for the government and other departments to formulate relevant policies. At present, the research on the forecast of FRI in China is still limited. There are few studies on FRI development structure, scale, production, and other indicators. In order to discuss the development trend of FRI in China, it is necessary to analyze its indicators. However, there are few data on FRI indicators since the supply-side structural reform only started in 2015. The sample size of the data is small. Statistical methods are not suitable for predicting these indicators. Fortunately, grey system theory is a suitable method for analyzing small sample size data. GM(1, 1 ) is the core model of the grey system, but it has some drawbacks. For time series with relatively large change rates, its prediction effect is not satisfactory. In response to these defects, many scholars have improved $\operatorname{GM}(1,1)$. Based on the effectiveness characteristics of short-term series forecasting, the fractional cumulative grey model (FGM) has been widely applied in various fields [4], including in the field of economic research and development [5]. Several studies have demonstrated that the accuracy of $\operatorname{FGM}(1,1)$ is higher than that of the traditional $\operatorname{GM}(1,1)[6] \operatorname{FGM}(1,1)$ not only has higher accuracy but also has better initial validity. In the case of $\operatorname{FGM}(1,1)$ equality perturbation, the sample size of the original series is proportional to the size of the perturbation boundary of the model [7]. This implies that from the perspective of stability, the model is relatively stable when the sample size is small. It not only has high 
stability and high fitting accuracy but also can add the weight of new information.

This paper uses $\operatorname{FGM}(1,1)$ to make predictions on corporate data in different FRIs. The forecast targets are the losses, inventory, finished products, assets, and total liabilities of the enterprises, as well as the revenue scale of the FRI. The reason for choosing these variables is that these are the most suitable indicators of industry change. First of all, the number and scale of enterprises comprehensively reflect the industry's market structure and industry development and operating capabilities. The number of enterprises is more convenient for statistics, so it is selected as the forecast target. In order to make the research more rigorous, a forecast of the number of loss-making companies has been added. Second, the output of products and the number of products in stock reflect the company's production capacity as well as the industry's market potential and growth. Sales volume is one of the indicators of enterprise size, and it can also reflect the development capacity of the industry to a certain extent. There are two ways of expressing this indicator, namely, sales volume and sales revenue, which is the sales scale. In addition, the industry's debt ratio indicates how much of the company's assets are debt. It can also be used to provide an indication of a company's long-term repayment ability and the stability of its financial position. The debt ratio is the ratio of total debt to total assets, and it is an important indicator of the debt ratio of the industry under study. The purpose of this paper is to analyze the development prospects of the industry and make recommendations through the observation of FRI development trends. It also provides a reference for investors who want to invest in FRI. The data on the enterprises in the FRI from 2013 to 2018 were obtained from the National Bureau of Statistics of China.

The structure of this paper is as follows. Section 2 is a literature review. Section 3 is the methodology and introduces the construction steps of $\operatorname{FGM}(1,1)$. Section 4 is the prediction and analysis of the data using $\operatorname{FGM}(1,1)$. Conclusions are presented in Section 5.

\section{Literature Review}

Ferrous metals are iron and its alloys, such as steel, pig iron, and ferroalloys. Ferrous metal smelting generally refers to melting iron ore into pig iron or smelting pig iron into steel billets [8]. FRI is a type of heavy industry and is divided into four industries: iron making, steel making, steel rolling, and ferroalloy smelting [9]. The production of heavy metal industry can have a serious impact on the environment if not well managed [10]. With the deterioration of the environment in recent years, people's awareness of environmental protection has gradually increased. The government has promulgated measures to promote green production in heavy industries. This requires enterprises to save energy, reduce emissions, and adjust the industrial structure. Similarly, in 2015, the supply-side structural reforms proposed by the Party Central Committee and Comrade Xi Jinping also required heavy industry companies to optimize the allocation of factors, with the aim of adjusting the economic structure and improving the quality and quantity of economic growth [11]. Structural reforms on the supply side include demand and supply. The demand-side reform mainly includes investment, consumption, and export, while the supply side has labor, land, capital, institutional creation, and innovation [12]. The supply-side structural reform can improve supply quality and use reforms to promote structural adjustment. It not only corrects the distortion of factor configuration but also expands the effective supply. It also improves the adaptability and flexibility of the supply structure to demand changes and increases total factor productivity [13]. For FRI, the main purpose of supply-side structural reform is to eliminate backward production capacity and improve product quality [14]. The FRI in China is greatly affected by the supply-side structural reform and environmental protection, and its economy loss is relatively high [15]. Some scholars have conducted research on the impact of supply-side structural reforms on the heavy industry. Zhang and Cui [16] analyzed how coal listed companies can assume social responsibilities with regard to supply-side reforms and ecological protection policies and the impact these policies may have on companies. Wang and Quan [17] found through research that supply-side decisionmaking reforms have a positive impact on enhancing innovation in enterprises. Tang et al. [18] studied the development of state-owned enterprises and heavy industry enterprises in China following the promulgation of supplyside structural reform policies.

Grey system theory can provide accurate predictions using small data sets and limited information [19]. In pursuit of higher prediction accuracy, scholars began to improve the traditional grey model after $\operatorname{GM}(1,1)$ was widely used in many fields. Lei et al. [20] proposed a novel grey prediction model based on $\operatorname{GM}(1,1)$, called neural ordinary differential grey model, with high prediction accuracy. Wang et al. [21] compared the $\operatorname{GM}(1,1)$ and discrete grey model $\operatorname{DGM}(1,1))$ in terms of prediction accuracy and found that $\operatorname{DGM}(1,1)$ has better stability. The $\operatorname{FGM}(1,1)$ used in this paper was proposed by Shi and $\mathrm{Wu}$ [22]. The introduction of the fractional-order cumulative generating operator makes the grey prediction model have better prediction performance compared with the traditional grey prediction model GM(1, 1). $\operatorname{FGM}(1,1)$ can weaken the randomness of the original data sequence during the operation, and the data fluctuation has less interference with the model prediction results, which can obtain a higher fitting accuracy (the construction principle of $\operatorname{FGM}(1,1)$ is shown in Figure 1). Therefore, this grey forecasting model is also commonly used as a forecasting tool by scholars [23]. Tu and Chen [24] used the unequal fractional-order discrete multivariable grey model to predict the public concern about air pollution in three cities of China. Liu et al. [25] used a fractional-order grey model to analyze the development trend of total retail sales of consumer goods in China and obtained some management insights from numerical examples. Wang and Li [26] analyzed the development trends of the eastern, central, and western regions of China by building a fractional-order multivariate grey model at the level of ecological environment and economic development. The main influencing 


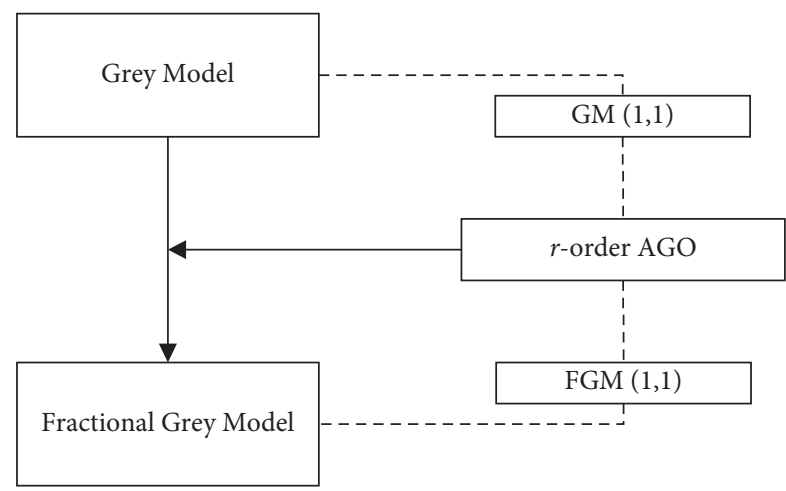

FIGURE 1: The construction principle of $\operatorname{FGM}(1,1)$.

factors of natural gas consumption in eastern, central, and western regions of China were analyzed by establishing a fractional-order multivariate grey model from the ecological environment and economic development levels.

\section{Methodology}

The composition of $\operatorname{FGM}(1,1)$ is to introduce the fractionalorder cumulant operator into the traditional grey univariate model $\operatorname{GM}(1,1)$. One indicator sequence is $Y^{(0)}=\left\{y^{(0)}(1), y^{(0)}(2), \ldots, y^{(0)}(n)\right\}$; the $\operatorname{FGM}(1,1)$ modeling process is as follows. By using

$$
Y^{(r)}=\sum_{i=1}^{k} C_{k-i+r-1}^{k-1} y^{(0)}(i)
$$

the $r$-order accumulation sequence is $Y^{(r)}=\left\{y^{(r)}(1)\right.$, $\left.y^{(r)}(2), \ldots, y^{(r)}(n)\right\}$.

Here,

$$
\begin{aligned}
C_{r-1}^{0} & =1, C_{k}^{k+1}=0, C_{k-1+r-1}^{k-1} \\
& =\frac{(k-i+r-1)(k-i+r-2) \cdots(r+1) r}{(k-1) !} .
\end{aligned}
$$

The first-order one-variable differential equation of the $r$-order cumulative sequence, $Y^{(r)}$, can be expressed as

$$
\frac{\mathrm{d} y^{(r)}(t)}{\mathrm{d} t}+a y^{(r)}(t)=b \text {. }
$$

Among them, $a$ is the development coefficient $b$ is the grey action quantity. The solution is

$$
y^{(r)}(t+1)=\left[y^{(0)}(1)-\frac{b}{a}\right] e^{-a t}+\frac{b}{a} .
$$

The parameters are obtained by using the least squares method. It enables to minimise the square sum of errors. The unknown parameters $\widehat{a}$ and $\widehat{b}$ are obtained by the following calculations:

$$
\left[\begin{array}{l}
\widehat{a} \\
\widehat{b}
\end{array}\right]=\left(A^{T} A\right)^{-1} A^{T} Z,
$$

where

$$
\begin{aligned}
Z & =\left[\begin{array}{c}
y^{(r)}(2)-y^{(r)}(1) \\
y^{(r)}(2)-y^{(r)}(1) \\
\vdots \\
y^{(r)}(n)-y^{(r)}(n-1)
\end{array}\right], \\
A & =\left[\begin{array}{cc}
-0.5 y^{(r)}(1)+y^{(r)}(2) & 1 \\
-0.5 y^{(r)}(2)+y^{(r)}(3) & 1 \\
\vdots & \vdots \\
-0.5 y^{(r)}(n-1)+y^{(r)}(n) & 1
\end{array}\right] .
\end{aligned}
$$

Entering $\hat{a}$ and $\hat{b}$ into the time response function $\widehat{y}^{(r)}(k+1)=\left[y^{(0)}(1)-(\widehat{b} / \widehat{a})\right] e^{-\widehat{a} k}+(\widehat{b} / \widehat{a}), \hat{y}^{(r)}(k+1)$ is the fitting value at the time $k+1$.

The predictive sequence of $\widehat{Y}^{(r)}=\left\{\widehat{y}^{(r)}(1)\right.$, $\left.\widehat{y}^{(r)}(2), \ldots, \widehat{y}^{(r)}(n)\right\}$ is

$$
\alpha^{r} \widehat{Y}^{(r)}=\left\{\alpha^{1} \widehat{y}^{(r)(1-r)}(1), \alpha^{1} \widehat{y}^{(r)(1-r)}(2), \ldots, \alpha^{1} \widehat{y}^{(r)(1-r)}(n)\right\},
$$

where $\alpha^{1} \widehat{y}^{(r)(1-r)}(k)=\widehat{y}^{(r)(1-r)}(k)-\widehat{y}^{(r)(1-r)}(k-1)$.

Therefore, the forecasting values are $\hat{y}^{(0)}(1), \widehat{y}^{(0)}$ $(2), \ldots, \widehat{y}^{(0)}(n)$.

The mean absolute percentage error (MAPE) is used to evaluate the model, and the calculation method is as follows:

$$
\text { MAPE }=100 \% \frac{1}{n} \sum_{k=1}^{n}\left|\frac{y^{(0)}(k)-\widehat{y}^{(0)}(k)}{y^{(0)}(k)}\right| .
$$

In summary, through the fractional-order accumulation generation process in $\operatorname{FGM}(1,1)$ and the model solving process, the model construction steps are summarized as follows:

Step 1. The original nonnegative sequence $Y^{(0)}=\left\{y^{(0)}(1), y^{(0)}(2), \ldots, y^{(0)}(n)\right\}$ is generated by the action of fractional-order accumulation to obtain the sequence $Y^{(r)}=\left\{y^{(r)}(1), y^{(r)}(2), \ldots, y^{(r)}(n)\right\}$.

Step 2. The order $r$ in the fractional-order cumulative generation is optimized in the case where the objective function is MAPE minimum. The parameters $a$ and $b$ are obtained according to the above equations.

Step 3. The time response equation of the $\operatorname{FGM}(1,1)$ model can be obtained by substituting the calculated parameters $a$ and $b$ into formula. Subsequently, the fitted and predicted values of the original series can be computed.

\section{Forecasting Results and Discussion}

4.1. Forecasting the Enterprise's Losses. The sample data are the number of enterprises from 2013 to 2017. The companies' number is taken as the example, and the $\operatorname{FGM}(1,1)$ model is developed to forecast the change in the companies' number in 2018-2022. The modeling process is as follows:

Step 1. The sequence of the enterprise is 


$$
Y^{(0)}=\{11034,10564,10071,9224,8545\} .
$$

The 0.84-order accumulation sequence is

$$
\begin{aligned}
Y^{(0.84)} & =\left\{y^{(0.84)}(1), y^{(0.84)}(2), y^{(0.84)}(3), y^{(0.84)}(4), y^{(0.84)}(5)\right\} \\
& =\{11034,19832.56,27471.84,33919.80,39553.89\}
\end{aligned}
$$

Step 2. The unknown parameters $\widehat{a}$ and $\widehat{b}$ are obtained by the following calculations:

$$
\left[\begin{array}{l}
\widehat{a} \\
\widehat{b}
\end{array}\right]=\left(A^{T} A\right)^{-1} A^{T} Z=\left[\begin{array}{c}
0.1506 \\
11140.61
\end{array}\right],
$$

where

$$
\begin{aligned}
Z & =\left[\begin{array}{l}
8798.56 \\
7639.28 \\
6447.96 \\
5634.09
\end{array}\right], \\
A & =\left[\begin{array}{ll}
-15433.28 & 1 \\
-23652.20 & 1 \\
-30695.82 & 1 \\
-36736.84 & 1
\end{array}\right] .
\end{aligned}
$$

Step 3. The time response function is

$$
\hat{y}^{(0.84)}(k+1)=\left(11034-\frac{11140.61}{0.1506}\right) e^{-0.1506 k}+\frac{11140.61}{0.1506} .
$$

Step 4. It can be obtained that

$$
\begin{aligned}
\widehat{Y}^{(0.84)} & =\left\{\hat{y}^{(0.84)}(1), \hat{y}^{(0.84)}(2), \hat{y}^{(0.84)}(3), \hat{y}^{(0.84)}(4), \hat{y}^{(0.84)}(5), \hat{y}^{(0.84)}(6), \hat{y}^{(0.84)}(7), \hat{y}^{(0.84)}(8), \hat{y}^{(0.84)}(9), \hat{y}^{(0.84)}(10)\right\} \\
& =\{11034,19833.52,27402.74,33913.65,39514.25,44331.78,48475.76,52040.33,55106.5357744 .02\} .
\end{aligned}
$$

Therefore,

$$
\begin{aligned}
\widehat{Y}^{(0.84)(0.16)}=\{ & \left\{\hat{y}^{(0.84)(0.16)}(1), \hat{y}^{(0.84)(0.16)}(2), \hat{y}^{(0.84)(0.16)}(3), \hat{y}^{(0.84)(0.16)}(4), \widehat{y}^{(0.84)(0.16)}(5), \hat{y}^{(0.84)(0.16)}(6),\right. \\
& \left.\cdot \widehat{y}^{(0.84)(0.16)}(7), \widehat{y}^{(0.84)(0.16)}(8), \widehat{y}^{(0.84)(0.16)}(9), \widehat{y}^{(0.84)(0.16)}(10)\right\} \\
= & \{11304,21598.96,31600.06,40875.89,49391.03,57163.68,64235.94,70660.00,76491.10,81783.94\} .
\end{aligned}
$$

The predictive sequence is

$$
\begin{aligned}
\hat{y}^{(0)} & =\left\{\hat{y}^{(0)}(1), \hat{y}^{(0)}(2), \hat{y}^{(0)}(3), \hat{y}^{(0)}(4), \hat{y}^{(0)}(5), \hat{y}^{(0)}(6), \hat{y}^{(0)}(7), \hat{y}^{(0)}(8), \hat{y}^{(0)}(9), \hat{y}^{(0)}(10)\right\} \\
& =\{11034,10564.96,10001.09,9275.84,8515.13,7772.65,7072.27,6424.06,5831.10,5292.83\} .
\end{aligned}
$$

A comparison of the fitted values with the actual values is shown in Figure 2.

The MAPE calculated by $\operatorname{FGM}(1,1)$ with the number of enterprises as the sample data is $0.4 \%$, which is much less than $10 \%$, indicating that $\operatorname{FGM}(1,1)$ is applicable to the calculation of this data set. The calculation process of other indicators is the same as this process. 


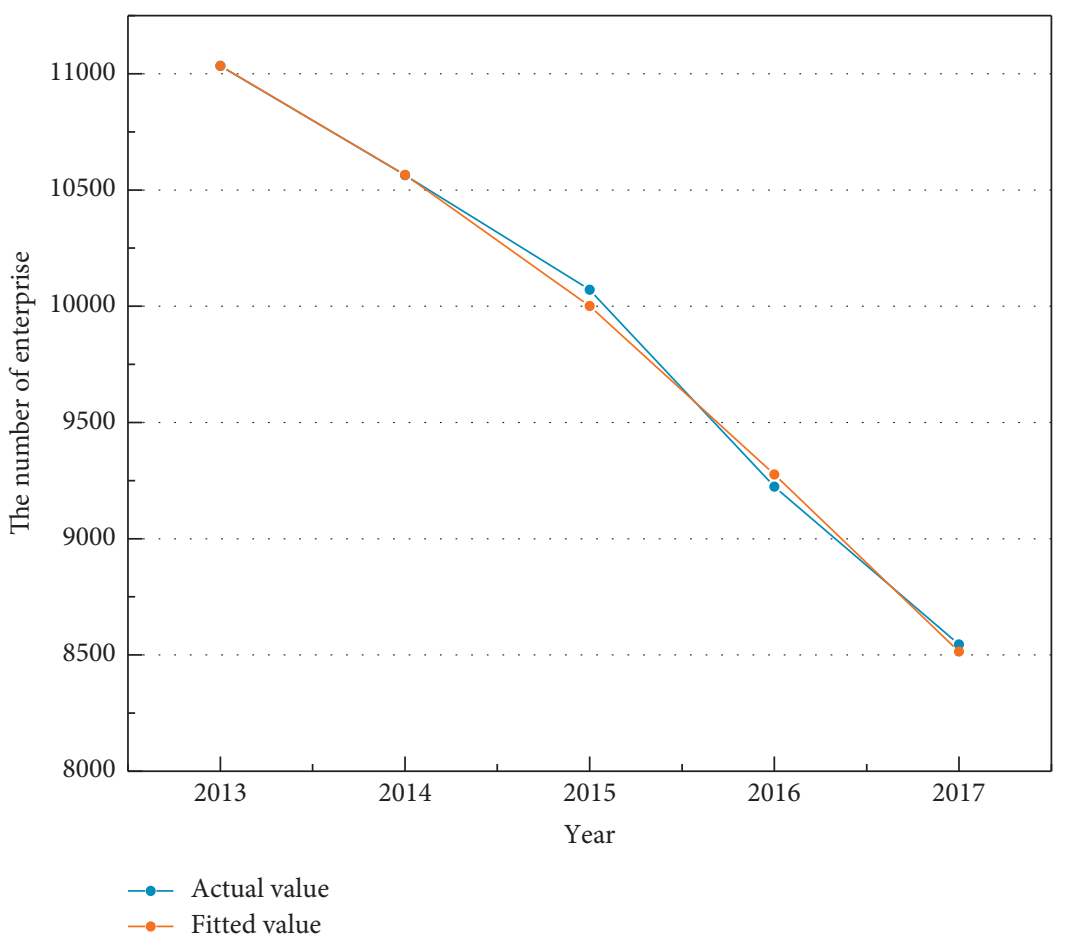

Figure 2: Comparison of actual value and fitting value.

The fitted and predicted values of the number of enterprises are derived based on the above calculation process. The fitted results and MAPE comparisons derived from $\operatorname{FGM}(1,1), \operatorname{DGM}(1,1)$, even $\operatorname{GM}(1,1)(\operatorname{EGM}(1,1))$, and original difference $\operatorname{GM}(1,1) \operatorname{CDGM}(1,1))$ for the same set of data are shown in Table 1 . The comparison of each model further illustrates the advanced nature of $\operatorname{FGM}(1,1)$.

The forecasting results of the $\operatorname{FGM}(1,1)$ indicate that the number of enterprises in 2018-2022 is decreasing continuously and will fall to 5293 by 2022, which is half of that in 2013 (Table 2). The number of loss-making enterprises declines at a slow rate and accounts for $13.3 \%$ of the total number of enterprises in 2022, which represents a $2 \%$ decrease compared with 2017.

The number of smelting and rolling processing enterprises in China was 8545 in 2017. Under the pressure of supply-side structural reform and environmental protection, the number of enterprises decreased by $23 \%$ compared with $2013(11,034)$. The number of enterprises declaring losses in 2015 was 2,210, accounting for $21.9 \%$ of the total number of enterprises. The number of enterprises declaring losses in 2017 dropped to 1,305 (Table 3). Although the number of loss-making enterprises is gradually decreasing, the percentage of the total number of enterprises is still high at $15.3 \%$. This implies that one out of every seven enterprises is declaring a loss.

One of the reasons for the rapid decline in the total number of enterprises is the relatively poor innovation capacity of enterprises. The issue arises in connection with the ability to upgrade the technology of products and the organizational structure of enterprises as well as their
TABLE 1: Comparison of fitting values of different models.

\begin{tabular}{lcccc}
\hline Year & FGM $(1,1)$ & $\operatorname{DGM}(1,1)$ & $\operatorname{EGM}(1,1)$ & ODGM $(1,1)$ \\
\hline 2013 & 11034.00 & 11034.00 & 11034.00 & 11034.00 \\
2014 & 10564.96 & 10655.98 & 10651.09 & 10654.94 \\
2015 & 10001.09 & 9919.51 & 9915.61 & 9919.27 \\
2016 & 9275.84 & 9233.94 & 9230.92 & 9234.39 \\
2017 & 8515.13 & 8595.75 & 8593.51 & 8596.80 \\
MAPE & $0.40 \%$ & $0.77 \%$ & $0.75 \%$ & $0.77 \%$ \\
\hline
\end{tabular}

TABle 2: The number of enterprise.

\begin{tabular}{lc}
\hline Year & Predicted value \\
\hline 2018 & 7773 \\
2019 & 7072 \\
2020 & 6424 \\
2021 & 5831 \\
2022 & 5293 \\
\hline
\end{tabular}

TABLE 3: The number of losing-market enterprise.

\begin{tabular}{lccc}
\hline Year & Fitted value & Year & Predicted value \\
\hline 2013 & 1946 & 2018 & 1199 \\
2014 & 2064 & 2019 & 1035 \\
2015 & 1862 & 2020 & 901 \\
2016 & 1620 & 2021 & 792 \\
2017 & 1394 & 2022 & 703 \\
MAPE & $8.91 \%$ & & \\
\hline
\end{tabular}

management capabilities. It ultimately leads to low market competitiveness. In addition, the market pressure on Chinese FRI is gradually increasing. The enterprises are actively 
seeking a way out of restructuring and integration, forced by external pressure. Thus, many companies are being swallowed up and merged. Furthermore, the debt ratio of enterprises is very high. It is possible for many enterprises to collapse due to the breakage of capital chain. It is considered to be the main means for Chinese FRI enterprises to maintain cash flow by borrowing new debts to pay off old ones. However, with the State Council's stricter regulation and control policies on overcapacity industries, the channels for these enterprises to borrow directly from banks are gradually being closed. Under the dual pressure of policies and the market, the number of enterprises has continued to decline; thus, the number of loss-making enterprises has also decreased.

4.2. Forecasting Inventory and Finished Products. From 2013 to 2015, the inventory showed a sharp downward trend and reached 6749.9. After a rebound in 2016, it began to decline again. As of 2017, the inventory of FRI was 7125.9 hundred million Yuan, and the finished product value was 2475.8 hundred million Yuan (Figure 3). It is observed that from 2018 to 2022, changes in inventories and finished products tended to be flat, and development was relatively stable (the modeled MAPEs for the inventory and finished product data sets were $3.20 \%$ and $2.43 \%$, respectively).

The marked decline in FRI inventory in 2015 and 2017 was mainly due to the impact of China's national policies. Therefore, China's traditional manufacturing capacity is generally surplus, and there is a problem of oversupply. In 2015 , to solve the problem of overcapacity, the "de-capacity" policy based on the supply-side structural reform was proposed by China's President Xi Jinping. In 2017, Premier Li Keqiang of the State Council identified the target for capacity reduction in the government work report. The rationalization of production capacity was accelerated by this policy, and the rationalization level of production capacity has been realized. Therefore, in 2015 and 2017, affected by the relevant policies and regulation, the inventory of the FRI was reduced, especially in 2015 the excess capacity was regulated. The forecasting results show that the development of inventory and finished products is stable. After 2018, it indicates that the implementation of the policy has promoted the steady development of the industry.

4.3. Forecasting Assets and Total Liabilities. In 2016, the assets of the FRI were 64445.1 hundred million Yuan, a decrease of $0.98 \%$ compared with the value in 2015. In 2017, the assets and liabilities of the industry were 63818 hundred million Yuan and 40902 hundred million Yuan, respectively, and the asset-liability ratio was $64.09 \%$ (Figure 4 ). The forecasting results indicate that by 2022 , the asset-liability ratio will be $51.62 \%$, representing a decrease of $15.83 \%$ compared with the value in 2013.

As shown in Figures 4 and 5, FRI's assets, liabilities, and asset-liability ratio have all increased in 2013-2014. Since 2015 , they have begun to show a continuous decline. It can be seen from Figure 1 that the debt ratio will drop to $51.62 \%$ in 2022, which is $15.83 \%$ lower than 2013.
However, it is worth noting that although industrial operations have improved, the current asset-liability ratio is still relatively high. The main reasons for the high assetliability ratio of the FRI are as follows. On the one hand, the production capacity has expanded rapidly in the early years, which led to the expansion of enterprises (or an increase in the number of new projects). It is difficult to maintain the capital requirements of enterprises by using their own funds. External financing is inevitably necessary. On the other hand, under the market orientation, the ferrous metal industry needs to upgrade its industrial structure. The structural adjustment requires large investment amounts and a long payback period. This depends largely on the financial system, especially bank loans.

In response to these problems, the FRI companies began to improve their profitability by reducing costs. They increased the net assets by increasing income and increasing profits. In addition, some high-debt companies have reached market-based debt-to-equity swap agreements. Debt-toequity swaps are a direct solution to the high debts of companies. In 2018, the National Development and Reform Commission, the Central Bank, and the Ministry of Finance and other seven ministries and commissions jointly issued the "Notice on Specific Policy Issues in the Implementation of Market-Oriented Banks' Debt-to-Equity Rights." This document loosened the implementation requirements in terms of the combination of stocks and bonds, sources of funds, targets of implementation, types of claims, and financial instruments. This policy has further promoted the implementation of debt-to-equity swaps and had a positive impact on reducing debt ratios. These companies' own adjustments and favorable policies are also the reasons that caused the debt ratio to decrease annually. With the continuous adjustment of the industrial structure, the industry is gradually being standardized, and the operational conditions are expected to improve.

4.4. Forecasting the Revenue Scale. The revenue scale fluctuated considerably, dropping sharply to 64605.70 in 2015. Compared with the amount of 75028.45 hundred million Yuan in 2014, it decreased by $13.89 \%$. Then in 2016, the industry resumed its growth. In 2017, the revenue of the industry was 67429.60 hundred million Yuan, an increase of $22.4 \%$ over the same period of the previous year (Table 4 ).

The prediction results of the $\operatorname{FGM}(1,1)$ show that after a brief decline in 2018, the scale of revenue will rise steadily in 2019-2022 and reach 88082.92 by 2022 .

In 2015, the focus of China's macroeconomic policy shifted to supply-side structural reforms and there was a significant withdrawal of capital from the futures market, resulting in price volatility and declines.

The scale of revenues started to increase in 2016, and the overall growth was due to the reasons listed below. To begin with, the implementation of "de-capacity" and the corresponding national policies provided new ideas for the development of FRI. Many backward industries were eliminated. As a result, some resources and capital were 


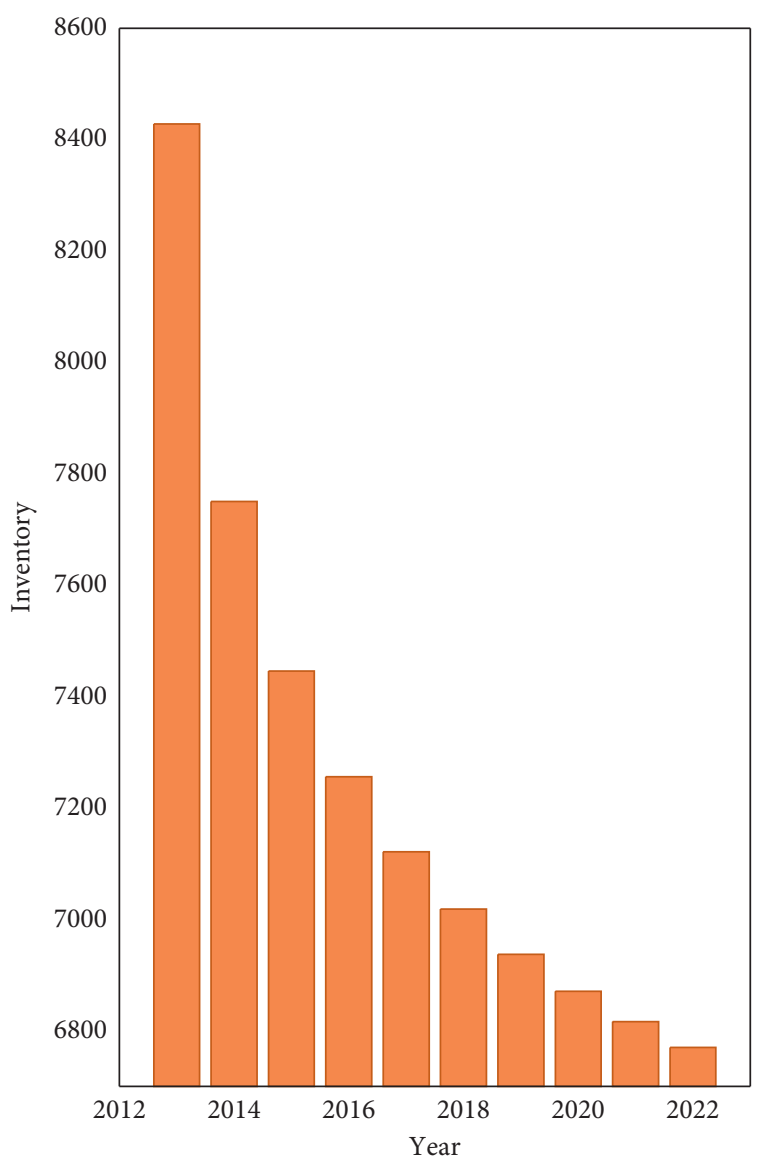

(a)

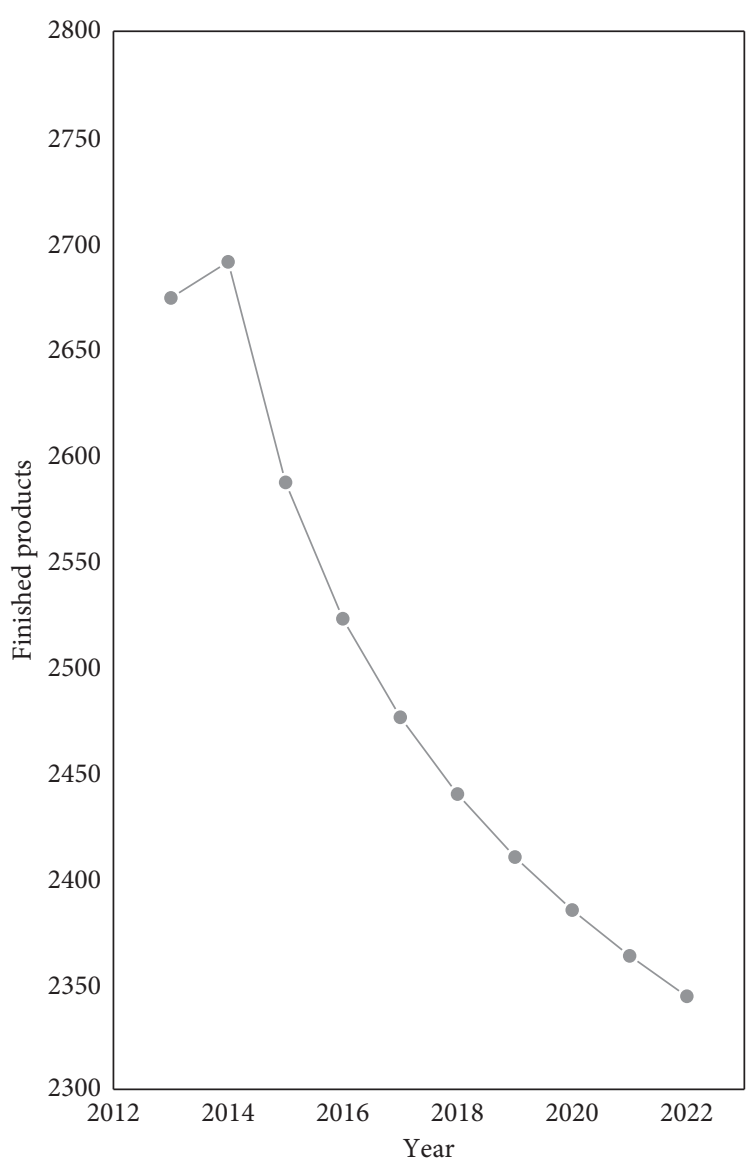

(b)

FIGURE 3: Model calculation results for (a) inventory and (b) finished products.

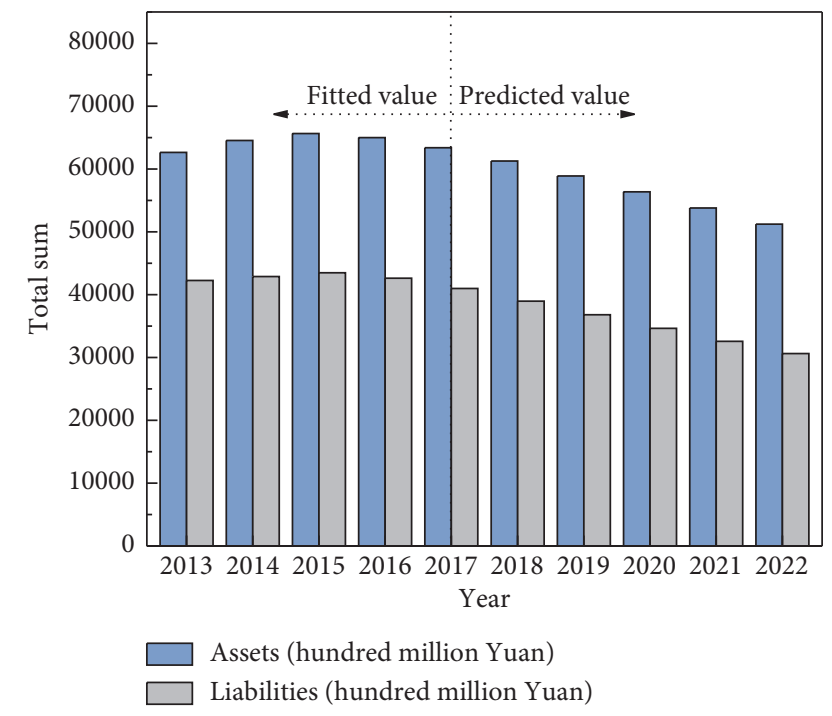

FIGURE 4: Model calculation results for FRI's assets and liabilities.

released and utilized more effectively. Moreover, based on the support of the Belt and Road Initiative and the definition of international division of labor, China's advanced technologies are exported along with other resources. Such development is highly sustainable. Furthermore, the

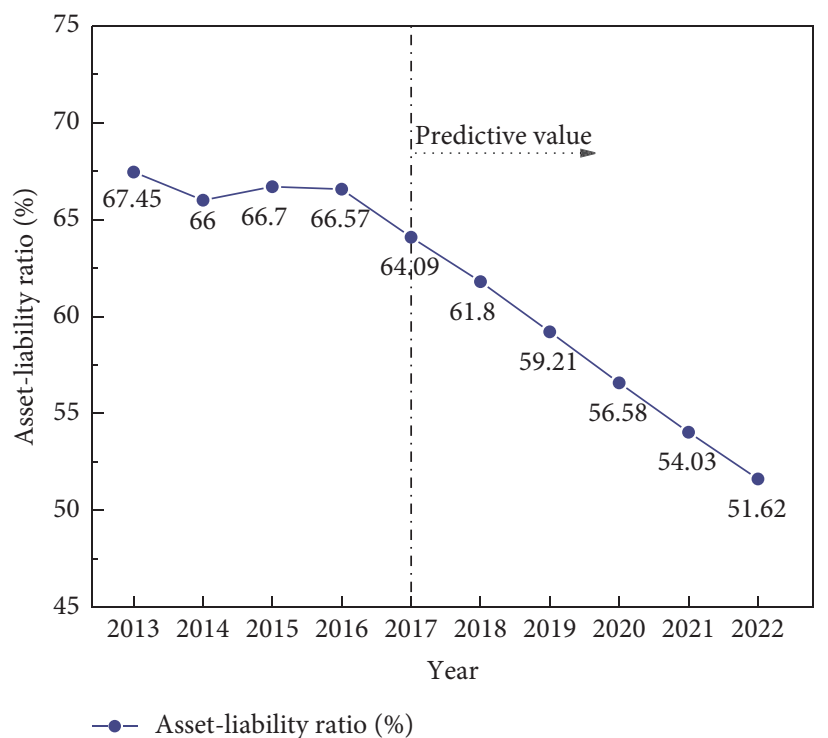

Figure 5: Trend of asset-liability ratio (\%).

expansion of international FRI is increasing with the economic rise of developing countries and the international demand for ferrous metals. This trend has contributed to the continued increase in market prices for international ferrous 
TABLE 4: Revenue scale (hundred million Yuan).

\begin{tabular}{lccc}
\hline Year & Fitted value & Year & Predicted value \\
\hline 2013 & 76316.93 & 2018 & 63227.03 \\
2014 & 68209.31 & 2019 & 65172.5 \\
2015 & 64911.45 & 2020 & 69202.97 \\
2016 & 63259.51 & 2021 & 76488.17 \\
2017 & 62696.86 & 2022 & 88983.92 \\
MAPE & $4.17 \%$ & & \\
\hline
\end{tabular}

metals in 2018. The revenue size of FRI in China is bound to be influenced by the international market.

\section{Conclusions}

In this paper, $\operatorname{FGM}(1,1)$ was used for the predictive analysis of the FRI data and the MAPEs were less than 10\% during the calculation. It indicates that the model is suitable for studying the problem in this field. The prediction results of $\operatorname{FGM}(1,1)$ demonstrate that the number of enterprises, inventories, and finished products in China's ferrous metal smelting and rolling industry will decrease annually due to the structural reform on the supply side and environmental pressure. The number of loss-making enterprises is on a downward trend. The trend of industrial assets, total liabilities, and gearing ratio will also decrease.

The revenue size started to increase after 2017. It shows that the industry is improving. In other words, FRI's decapitalization has achieved milestones. As the decapacity measures continue to strengthen and the industrial structure is adjusted, the profitable development pattern of the FRI in China is likely to maintain the relatively high prices of ferrous metals.

Considering the development status of China's foreign direct investment, the following suggestions are made for China's FRI. First of all, it is necessary to adopt innovative thinking to accelerate the extension of the industrial chain. Extension of the industrial chain helps solve the problem of overcapacity, it also helps seeking new sources of power and improving market competitiveness. This is the most effective way to enhance traditional industries. The second is to promote investor diversification and optimize resource allocation, thereby adjusting the industrial layout to avoid diversified investment and repeated construction. It is also necessary to increase the scale of income by adjusting product structure and reducing production costs.

\section{Data Availability}

The data used to support the findings of this study are available from the corresponding author upon request.

\section{Conflicts of Interest}

The authors declare that they have no conflicts of interest.

\section{Acknowledgments}

The relevant research studies in this paper are supported by the Humanities and Social Sciences Planning Projects of Ministry of Education (20YJAZH141).

\section{References}

[1] L. Z. Zhang and X. H. Liu, "Evaluating ecological efficiency of Chinese industrial enterprise," Renewable Energy, vol. 178, pp. 679-691, 2021.

[2] Q. H. Huang, "New drivers of China's industrial growth in its late-stage industrialization and new normal," China Economist, vol. 3, pp. 4-14, 2016.

[3] W. G. Liu, H. B. Zuo, J. S. Wang, and Q. G. Xue, "The production and application of hydrogen in steel industry," International Journal of Hydrogen Energy, vol. 46, no. 17, pp. 10548-10569, 2021.

[4] L. F. Wu, S. F. Liu, Z. G. Fang, and H. Y. Xu, "Properties of the $\mathrm{GM}(1,1)$ with fractional order accumulation," Applied Mathematics and Computation, vol. 252, pp. 287-293, 2015.

[5] Q. Xiao, M. Shan, M. Gao, and X. Xiao, "Evaluation of the coordination between China's technology and economy using a grey multivariate coupling model," Technological and Economic Development of Economy, vol. 27, no. 1, pp. 24-44, 2021.

[6] W. S. Jiang, Z. Y. Wang, and J. Lv, "A fractional-order accumulative regularization filter for force reconstruction," Mechanical Systems and Signal Processing, vol. 101, pp. 405423, 2018.

[7] M. Gao, H. Yang, Q. Xiao, and M. Goh, "A novel fractional grey Riccati model for carbon emission prediction," Journal of Cleaner Production, vol. 282, Article ID 124471, 2021.

[8] G. Cai, M. Ebrahimi, G. Zheng, and A. H. Kaksonen, "Effect of ferrous iron loading on dewaterability, heavy metal removal and bacterial community of digested sludge by Acidithiobacillus ferrooxidans," Journal of Environmental Management, vol. 295, Article ID 113114, 2021.

[9] J. B. Huang, Y. M. Luo, and C. Feng, "An overview of carbon dioxide emissions from China's ferrous metal industry: 1991-2030," Resources Policy, vol. 62, pp. 541-549, 2019.

[10] S. Z. Salleh, A. H. Yusoff, S. K. Zakaria, and M. A. A. Taib, "Plant extracts as green corrosion inhibitor for ferrous metal alloys: a review," Journal of Cleaner Production, vol. 304, Article ID 127030, 2021.

[11] M. Yu, X. T. Zhao, and Y. N. Gao, "Factor decomposition of China's industrial electricity consumption using structural decomposition analysis," Structural Change and Economic Dynamics, vol. 51, pp. 67-76, 2019.

[12] D. B. Fang, P. Hao, Q. Yu, and J. C. Wang, "The impacts of electricity consumption in China's key economic regions," Applied Energy, vol. 267, Article ID 115078, 2020.

[13] X. N. Guo and S. R. Lu, “Analysis of China's potential economic growth rate under the background of supply-side structural reform," Economist, vol. 1, pp. 29-40, 2018.

[14] X. C. Jiang, J. H. N. Shen, C. C. Lee, and C. Chen, "Supply-side structural reform and dynamic capital structure adjustment: evidence from Chinese-listed firms," Pacific-Basin Finance Journal, vol. 65, Article ID 101482, 2021.

[15] X. H. Zhu, A. Q. Zeng, M. R. Zhong, J. B. Huang, and H. P. Qu, "Multiple impacts of environmental regulation on the steel industry in China: a recursive dynamic steel industry chain CGE analysis," Journal of Cleaner Production, vol. 210, pp. 490-504, 2019.

[16] Y. X. Zhang and M. Z. Cui, "The impact of Corporate Social Responsibility on the enterprise value of China's listed coal enterprises," The Extractive Industries and Society, vol. 7, pp. 138-145, 2020.

[17] X. F. Wang and F. G. Quan, "The study of innovation path under the supply-side structural reform," Shanghai Journal of Economics, vol. 3, pp. 3-12, 2016. 
[18] K. Tang, Y. Qiu, and D. Zhou, "Does command-and-control regulation promote green innovation performance? Evidence from China's industrial enterprises," The Science of the Total Environment, vol. 712, Article ID 136362, 2020.

[19] K. H. Shi and L. F. Wu, "Modelling the relationship between population density and air quality using fractional Hausdorff grey multivariate model," Kybernetes, vol. 50, no. 11, 2021.

[20] D. J. Lei, K. L. Wu, L. P. Zhang, and W. S. Li, "Neural ordinary differential grey model and its applications," Expert Systems with Applications, vol. 177, Article ID 114923, 2021.

[21] Z. X. Wang, D. D. Li, and H. H. Zeng, "Model comparison of $\operatorname{GM}(1,1)$ and $\operatorname{DGM}(1,1)$ based on Monte-Carlo simulation," Physica A: Statistical Mechanics and Its Applications, vol. 542, Article ID 123341, 2020.

[22] K. H. Shi and L. F. Wu, "Forecasting air quality considering the socio-economic development in Xingtai," Sustainable Cities and Society, vol. 61, Article ID 102337, 2020.

[23] Q. Xiao, M. Shan, M. Gao, and X. Xiao, "Parameter optimization for nonlinear grey Bernoulli model on biomass energy consumption prediction," Applied Soft Computing, vol. 95, Article ID 106538, 2020.

[24] L. Tu and Y. Chen, "An unequal adjacent grey forecasting air pollution urban model," Applied Mathematical Modelling, vol. 99, pp. 260-275, 2021.

[25] C. Liu, W. L. Xie, W. Z. Wu, and H. G. Zhu, "Predicting Chinese total retail sales of consumer goods by employing an extended discrete grey polynomial model," Engineering Applications of Artificial Intelligence, vol. 102, Article ID 104261, 2021.

[26] J. L. Wang and N. Li, "Influencing factors and future trends of natural gas demand in the eastern, central and western areas of China based on the grey model," Natural Gas Industry B, vol. 7, no. 5, pp. 473-483, 2020. 